Rabaska

Revue d'ethnologie de l'Amérique française

\title{
Laboratoire de muséologie et d'ingénierie de la culture (LAMIC) (Université Laval)
}

\section{Philippe Dubé}

Volume 15, 2017

URI : https://id.erudit.org/iderudit/1041165ar

DOI : https://doi.org/10.7202/1041165ar

Aller au sommaire du numéro

Éditeur(s)

Société québécoise d'ethnologie

ISSN

1703-7433 (imprimé)

1916-7350 (numérique)

Découvrir la revue

Citer ce document

Dubé, P. (2017). Laboratoire de muséologie et d'ingénierie de la culture (LAMIC)

(Université Laval). Rabaska, 15, 318-320. https://doi.org/10.7202/1041165ar d'utilisation que vous pouvez consulter en ligne.

https://apropos.erudit.org/fr/usagers/politique-dutilisation/ 


\section{Laboratoire de muséologie et d'ingénierie de la culture (LAMIC)}

Pavillon Casault, local 3645-Z Téléphone: (418) 656-2131, poste 3822

Université Laval

Québec (Québec) G1V 0A6

Courriel: Philippe.Dube@hst.ulaval.ca

Toile: www.lamic.ulaval.ca

\section{Dix ans déjà}

Le Laboratoire de muséologie et d'ingénierie de la culture (LAMIC) a officiellement ouvert ses portes au printemps 2007 après avoir reçu un financement substantiel de la Fondation canadienne de l'innovation (FCI) en 2004. En tant qu'infrastructure de recherche spécialisée en muséologie, ce laboratoire, centré sur les modes de transmission de la culture et du patrimoine en situation de muséalité, sera éventuellement relayé à une nouvelle instance responsable après dix années d'activité scientifique dont nous tenterons ici de faire brièvement le bilan à titre de fondateur-directeur. Puisque nous quittons l'Université Laval en septembre 2017, après y avoir consacré près de 30 ans de notre exercice professionnel comme professeur de muséologie (entré en fonction en novembre 1988), nous devrions pouvoir anticiper un avenir pour cette plateforme dédiée à l'usage du médium numérique en musée. Malheureusement, nous ne pourrons pas aborder cet aspect pourtant crucial de son devenir. En revanche, nous allons pouvoir esquisser, en guise de bilan, une vue d'ensemble des dix dernières années et tenter, en conclusion, d'en tirer une leçon qui pourra servir à nos successeurs en livrant sommairement l'expérience de la première décennie de cette infrastructure de recherche.

Premièrement, nous devons reconnaître que, pour obtenir l'octroi pour créer une nouvelle infrastructure, le concours de la Fondation canadienne de l'innovation $(\mathrm{FCI})$ a exigé un travail rigoureux de notre part et particulièrement celle de François Côté, aujourd'hui conseiller à la mise en valeur du patrimoine, Division des arts et du patrimoine, Ville de Québec, qui a mené avec compétence l'opération de rédaction de cette demande et celle, non moins indispensable, de Christian Marcotte, aujourd'hui directeur du Musée régional de la Côte-Nord, qui y a dirigé l'opération d'acquisition du matériel muséographique et technologique. En tant que trio, nous devions faire preuve de beaucoup d'imagination tout en respectant les règles que nous imposait le programme subventionnaire. Nous avons su développer un modèle de laboratoire en muséologie qui n'avait aucun exemple dans le monde. Ce projet blanc, comme on dit, a été pensé à partir de trois éléments qui fondent le musée, selon notre appréciation : le visiteur, l'objet et l'espace.

Cette trilogie presque méthodologique aura nourri, sinon structuré, notre réflexion tout au long de cette première décennie. Jusqu'à tout récemment, nous n'avions pas remis en question cette figure paradigmatique qui nous semblait, par ces trois composantes, former l'ADN du musée. Cependant, suite aux brillants travaux doctoraux d'Alexia Fontaine (Lille3-UL), rattachée au LAMIC, nous avons reconsidéré ce cas de figure tripode pour l'amener finalement à quatre points, puisque le professionnel de musée a aussi sa part à dire dans le développement de l'institution muséale. Il s'agit donc de reconnaître, après cette révision structurelle, que l'objet, le professionnel, le visiteur et l'espace sont considérés maintenant à parts égales dans cette nouvelle 
configuration épistémologique en forme de quadrilogie pour nos travaux futurs (régimes de muséalité).

Après dix ans d'existence, nous ne nous doutions pas du possible dépassement de cette « sainte trinité » que formait le musée, selon notre prime proposition en guise d'énoncé épistémique. Aujourd'hui, nous devons nous raviser et prendre en compte un élément fondateur du musée, soit l'acteur ou l'actrice qui le module selon ses besoins et les moyens à sa disposition. De nouvelles perspectives s'ouvrent du point de vue de l'avancement des connaissances en muséologie en intégrant justement une dimension de la praxis au modèle théorique de départ. C'est dire combien l'ethnologie prend ici tout son sens en incorporant le porteur, voire même le changeur de tradition dans la pratique du métier de muséologue.

Ce changement paradigmatique nous permet aujourd'hui de porter un regard plus critique sur ce que nous avons pu accomplir durant ces dix dernières années. Outre la longue mise en place de l'infrastructure, selon les plans de l'architecte-muséologue Caroline Lajoie (Bisson et Associés) où Louis-Robert Bouchard (aujourd'hui artiste et artisan du numérique ElBy studio : www.elbystudio.ca) et Lydia Bhérer-Vidal (aujourd'hui coordonnatrice de programme et conseillère en muséologie, Direction de la coordination des interventions territoriales et du développement culturel numérique, Ministère de la Culture et des communications du Québec) ont assuré les bases de cette instance de recherche qui se voulait, pour l'essentiel, expérimentale et active, principalement, au chapitre de l'expographie.

Parmi les nombreux projets, tant artistiques que muséographiques, qui ont animé ce pôle expérimental, il y a la numérisation 3D du Monastère des Ursulines de Québec présenté sur le site du Musée virtuel du Canada (www.monastere3d.com/ index.html) qui aura été le point de convergence de plusieurs de nos activités en regard de l'objet réel / l'objet virtuel, la dimension spatiale de tout projet muséal (la «muséomatique »), la présence du son dans l'exposition, la fluidité du parcours de visite, la puissance du récit, la révélation du sens de l'objet, etc. Autant de thèmes qui ont traversé les travaux de la doctorante Dominique Gélinas (coordonnatrice du LAmIC jusqu'à sa nomination au poste de conservatrice de l'histoire sociale au Musée du Nouveau-Brunswick en octobre 2016) qui vient d'ailleurs de terminer sa thèse avec brio.

S'il y a un enseignement global à tirer de cette expérience de longue haleine en matière de recherche expérimentale, c'est qu'il faut un projet-moteur pour non seulement propulser la machine en quelque sorte, mais aussi alimenter intellectuellement le laboratoire en action. Le nerf de la guerre, comme on dit couramment, est de pouvoir soutenir une équipe de chercheurs suffisamment mobilisée autour d'une thématique centrale (sujet de recherche) pour aller en profondeur et mener à bien un projet structurant pour le laboratoire. À ce sujet, le projet de la numérisation 3D du Monastère des Ursulines de Québec a su au fil des ans (de 2010 à aujourd'hui) générer sa bonne part d'activités à cause de la multiplicité et du croisement des problématiques qui se sont imposées sur notre route. D'abord, la captation numérique d'un lieu reconnu comme privé - pour ne pas dire sacré - a demandé un doigté que la directrice-conservatrice du Musée des Ursulines de Québec, Madame Christine Cheyrou, a maîtrisé avec art. Sans son intermédiaire, nous n'aurions pas pu réussir 
cette belle aventure. L'autre grande difficulté rencontrée se loge dans la technologie qui évolue très rapidement et, sans l'accompagnement compétent de Benoît Duinat (chercheur en géomatique, UL), nous aurions été littéralement bloqués à plusieurs étapes de ce projet. Je ne voudrais pas ici énumérer tous les collaborateurs et collaboratrices de cette production puisque les crédits sont attribués sur le site même du Mvc (www.monastere3d.com/index.html).

Somme toute, on doit comprendre qu'un projet d'envergure comme la numérisation 3D du Monastère des Ursulines de Québec a eu la capacité de charpenter, sur plusieurs années, le fonctionnement au quotidien d'une organisation de cet ordre. À notre avis, plus un projet est important en volume, plus il peut agréger les ressources humaines et financières nécessaires au développement d'un tel laboratoire. À ce propos, nous avons certainement raté quelques belles occasions qui auraient pu dynamiser davantage notre infrastructure. Mais une lecture du parcours accompli ces dix dernières années nous aura appris qu'un suivi serré de la part des instances universitaires responsables en matière de recherche se doit d'être offert à ce type de structures émergeantes qui explorent avec audace de nouveaux domaines en sciences humaines (humanités numériques). Si nous avions une recommandation à faire, c'est que l'université d'accueil apprenne à se soucier davantage de ses «nouveau-nés » qui font la difficile expérience par eux-mêmes de la recherche à incidence hautement technologique alors que d'autres secteurs, comme les sciences pures en général, ont une longue expérience des enjeux que posent ce type de recherche qui souffre rapidement de l'obsolescence technologique pour devenir un handicap majeur à son propre développement. L'institution universitaire d'accueil doit globalement revoir son approche à cet égard où, notamment, la culture et la technologie tissent des liens d'intime complicité dont le succès de l'un dépend directement de celui de l'autre. Dans le cas qui nous occupe, elles sont toutes deux imbriquées l'une dans l'autre et un accompagnement doit leur être assigné pour que les deux puissent enfin se tresser autour d'un même axe, sans quoi l'insuffisance énergétique de l'équipe viendra à bout de toute infrastructure qui doit à la fois faire preuve d'audace (oser) et en même temps se maintenir en place (conserver ses acquis) si elle veut se développer normalement. Une sorte de bicéphalité (cas d'exception) auquel toute institution responsable doit porter une attention particulière et en prendre le plus grand soin, surtout durant les années de croissance. On doit songer à une sorte d'incubateur qui aurait la vocation d'accompagner le démarrage de structures naissantes comme l'Itis de l'Université Laval le promettait pourtant à l'époque de sa création. L'université a le devoir somme toute de veiller à tout ce qu'elle crée. Surtout quand ses créatures sont elles-mêmes créatrices de nouveaux savoirs et des nouvelles compétences qu'elles génèrent. En espérant ces quelques mots utiles au devenir prochain d'une nouvelle infrastructure qui viendra prendre le relais d'une qui aura fêté ses dix ans d'existence en 2017.

Phillppe Dubé 